\title{
Taxonomic description and phylogenetic placement of two new species of Spalangiopelta (Hymenoptera: Pteromalidae: Ceinae) from Eocene Baltic amber
}

\author{
Marina Moser ${ }^{\text {Corresp., } 1,2}{ }^{,}$, Roger A Burks ${ }^{3}$, Jonah M Ulmer ${ }^{1,2}{ }^{2}$, John M Heraty ${ }^{3}$, Thomas van de Kamp $^{4,5}$, Lars \\ Krogmann ${ }^{\text {Corresp. 1, } 2}$ \\ 1 Department of Entomology, State Museum of Natural History Stuttgart, Stuttgart, Deutschland \\ 2 Institute of Biology, Systematic Entomology (190n), University of Hohenheim, Stuttgart, Germany \\ 3 Department of Entomology, University of California Riverside, Riverside, California, USA \\ 4 Institute for Photon Science and Synchrotron Radiation (IPS), Karlsruhe Institute of Technology (KIT), Eggenstein-Leopoldshafen, Germany \\ 5 Laboratory for Applications of Synchrotron Radiation, Karlsruhe Institute of Technology (KIT), Karlsruhe, Germany \\ Corresponding Authors: Marina Moser, Lars Krogmann \\ Email address: marina.moser@smns-bw.de, lars.krogmann@smns-bw.de
}

Spalangiopelta is a small genus of chalcid wasps that has received little attention despite the widespread distribution of its extant species. The fossil record of the genus is restricted to a single species from Miocene Dominican amber. We describe two new fossil species, Spalangiopelta darlingi sp. n. and Spalangiopelta semialba sp. n. from Baltic amber. The species can be placed within the extant genus Spalangiopelta based on the distinctly raised hind margin of the mesopleuron. 3D models reconstructed from $\mu \mathrm{CT}$ data were utilized to assist in the descriptions. Furthermore, we provide a key for the females of all currently known Spalangiopelta species. The phylogenetic placement of the fossils within the genus is analyzed using parsimony analysis based on morphological characters. Phylogenetic and functional relevance of two wing characters, admarginal setae and the hyaline break, are discussed. The newly described Baltic amber fossils significantly extend the minimum age of Spalangiopelta to the Upper Eocene. 
1 Taxonomic description and phylogenetic placement of two new

2 species of Spalangiopelta (Hymenoptera: Pteromalidae: Ceinae) from

3 Eocene Baltic amber

4 Marina Moser ${ }^{1,2}$, Roger A. Burks ${ }^{3}$, Jonah M. Ulmer ${ }^{1,2}$, John M. Heraty ${ }^{3}$, Thomas van de

5 Kamp $^{4,5}$, Lars Krogmann ${ }^{1,2}$

61 Department of Entomology, State Museum of Natural History Stuttgart, Rosenstein 1,

770191 Stuttgart, Germany

82 Institute of Biology, Systematic Entomology (190n), University of Hohenheim,

9 Garbenstr. 30b, 70599 Stuttgart, Germany

${ }^{3}$ Department of Entomology, University of California Riverside, Riverside, CA, USA

${ }^{4}$ Institute for Photon Science and Synchrotron Radiation (IPS), Karlsruhe Institute of

Technology (KIT), Hermann-von-Helmholtz-Platz 1, 76131 Eggenstein-Leopoldshafen,

13 Germany

${ }^{5}$ Laboratory for Applications of Synchrotron Radiation, Karlsruhe Institute of

15 Technology (KIT), Kaiserstr. 1, 76131 Karlsruhe, Germany

Corresponding Authors:

Marina Moser ${ }^{1,2}$

Department of Entomology, State Museum of Natural History Stuttgart, Rosenstein 1, 2170191 Stuttgart, Germany

22 Email address: marina.moser@smns-bw.de

Lars Krogmann ${ }^{1,2}$

24 Department of Entomology, State Museum of Natural History Stuttgart, Rosenstein 1, 2570191 Stuttgart, Germany

Email address: lars.krogmann@smns-bw.de 


\section{Abstract}

Spalangiopelta is a small genus of chalcid wasps that has received little attention despite the widespread distribution of its extant species. The fossil record of the genus is restricted to a single species from Miocene Dominican amber. We describe two new fossil species, Spalangiopelta darlingi sp. $\mathrm{n}$. and Spalangiopelta semialba sp. $\mathrm{n}$. from Baltic amber. The species can be placed within the extant genus Spalangiopelta based on the distinctly raised hind margin of the mesopleuron. 3D models reconstructed from $\mu \mathrm{CT}$ data were utilized to assist in the descriptions. Furthermore, we provide a key for the females of all currently known Spalangiopelta species. The phylogenetic placement of the fossils within the genus is analyzed using parsimony analysis based on morphological characters. Phylogenetic and functional relevance of two wing characters, admarginal setae and the hyaline break, are discussed. The newly described Baltic amber fossils significantly extend the minimum age of Spalangiopelta to the Upper Eocene.

\section{Introduction}

Ceinae is a small subfamily of Pteromalidae within the megadiverse Chalcidoidea. The subfamily contains three genera, two of which are monotypic (Mitroiu 2016): Bohpa Darling 1991, which is known only from South Africa, and Cea Walker 1837, which is found throughout the Western Palearctic region. The genus Spalangiopelta Masi 1922 comprises 14 extant species, eight of which are known only from the Palearctic region, whereas the other six species are Nearctic or Neotropic (Darling 1991, Mitroiu 2016). In addition, Darling (1996) described Spalangiopelta georgei, a fossil from Dominican amber.

Specimens of Ceinae are rarely represented in collections (Darling 1991). To date, the biology and life history strategies of members of the subfamily are virtually unknown with the exception of two host records: Spalangiopelta alata Bouček 1953 was observed emerging from a leaf mine of the herbivorous drosophilid Scaptomyza flava (Fallén 1823) (Diptera: Drosophilidae, originally cited as Scaptomyza flaveola Meigen 1830) on Cakile maritima Scopoli (Brassicaceae) (Bouček 1961). In addition, Cea pulicaris Walker 1837 was reared from Phytomyza pauliloewii Hendel 1920 (Diptera: Agromyzidae) on Peucedanum oreoselinum (L.) Moench (Apiaceae) (Bouček 1961). The morphology of the mesosoma, which displays either a distinctly arched or a flattened configuration led to the assumption that Spalangiopelta females are associated with leaf litter and duff habitats (Darling 1991). From these findings it would seem that leaf-mining Diptera living in confined habitats are the hosts of Spalangiopelta. 
63 At the time of description, the Dominican amber fossil S. georgei was dated to the

64 Oligocene based on an age estimate of 23 and 30 million years (Darling 1996; Grimaldi 65 1995). However, more recent estimates on the age of Dominican amber reach from 15

66 to 20 million years with the highest density of resin-producing trees in the Miocene 16

67 million years ago (Iturralde-Vinent \& MacPhee 1996; Iturralde-Vinent 2001). This

68 reduces the previously assumed minimum age of Spalangiopelta considerably.

69 Baltic amber was formed during the Eocene but there is still considerable debate 70 concerning its exact age and origin. Equally, the botanical origin of Baltic amber has 71 remained the subject of scientific debate for decades and was portentously dubbed 72 "The Tertiary Baltic Amber Mystery" (Langenheim 2003). Conservative studies build 73 upon an allochthonous redeposition of Baltic amber into layers of Blaue Erde (Blue 74 Earth) and therefore deduce an age at least matching that of the surrounding layers. 75 Following this assumption, estimates of the age of Baltic amber range from 35 to 55 million years (Poinar 1992 and references therein) with several authors giving a narrower range of 40 to 47 million years (Burleigh \& Whalley 1983; Grimaldi 1995; Grimaldi 1996; Ritzkowski 1997). In contrast, another theory has emerged in recent years: based on the hypothesis that locality and time of the formation of Baltic amber do not differ significantly from its deposition in marine sediments, an age for Baltic amber of 35 to 43 million years was inferred (Sadowski et al. 2017; Standke 2008).

The current study addresses two fossil specimens of Spalangiopelta (Chalcidoidea: Ceinae) from Eocene Baltic amber, which fall within the known geographic range of extant Palearctic Spalangiopelta species. The study has the following objectives: (1) Taxonomic description of two fossil wasp specimens from Baltic amber, complemented by digital images, scientific illustrations and 3D models reconstructed from $\mu \mathrm{CT}$ data. (2)

Development of a morphological key to enable the identification of extant and fossil Spalangiopelta species. (3) Phylogenetic placement of the two fossil specimens based on the cladistic analysis of morphological characters. As the oldest fossils of Spalangiopelta described so far, the two fossils extend the minimum age of Spalangiopelta to the upper Eocene and thus more than double the minimum age of the genus.

\section{Materials \& Methods}

\section{Specimen description and terminology}

Both holotypes (Figure 1 to 5) are deposited at the State Museum of Natural History 
100 description format largely follows Darling (1996), allowing comparison between the

101 amber fossils of Spalangiopelta.

\section{Morphological description and imaging}

103

104

105

106

107

108

109

110

111

112

113

114

115

116

117

118

119

120

121

122

123

124

125

126

127

128

129

130

131

132

133

134

Observations, descriptions and scoring of morphological characters (Table 1) were compiled using a Leica M205C stereo microscope with a 7.8 to $160 x$ magnification. The illustration of Spalangiopelta darlingi $\mathrm{sp}$. $\mathrm{n}$. was made with the same equipment with a camera lucida attached (Fig. 1). A MZ 16 APO Leica R microscope with an attached DXM 1200 Leica $R$ camera was used for habitus imaging with subsequent stacking of images in Helicon focus version 7.6.1 (Helicon Soft Ltd, Kharkov, Ukraine). Stacking followed the pyramid approach (method $C$ ) with the smoothing parameter setting of 4 to reduce image artefacts. Detail images were taken with a Keyence VHX 5000 digital microscope. Exact measurements given in Table 2 were taken in Amira based on the 3D models. All images were processed and figures were assembled in Adobe Photoshop version CS5.1 (Adobe Systems Software Ireland Ltd, Dublin, Ireland).

\section{$\mu \mathrm{CT}$ reconstruction}

Synchrotron-based X-ray microtomography was performed at the imaging cluster of the KIT light source at Karlsruhe Institute of Technology, Germany. We used a parallel polychromatic X-ray beam produced by a $1.5 \mathrm{~T}$ bending magnet that was spectrally filtered by $0.5 \mathrm{~mm}$ aluminium. A fast indirect detector system was employed, consisting of a $12 \mu \mathrm{m}$ LSO:Tb scintillator (Cecilia et al. 2011), diffraction-limited optical microscope (Optique Peter) coupled with a 12bit pco.dimax high speed camera with 2016 × 2016 pixels. Scans were done by taking 3,000 projections at $70 \mathrm{fps}$ and an optical magnification of 10X, resulting in an effective pixel size of $1.22 \mu \mathrm{m}$. Tomographic reconstruction was performed by the UFO framework (Vogelgesang et al. 2012). Reconstruction of the 3D surface model followed the methodology described by Ruthensteiner \& Hess (2008) and van de Kamp et al. (2018). The tomogram images were imported into Amira 6.5.0 (Thermo Fisher Scientific, Waltham, MA, U.S.A.) and preliminary volume renderings were created, giving an overview of the fossils. The models were segmented with the segmentation editor in Amira by labelling every tenth slice. The labels served as input for subsequent semi-automatic segmentation using the software "Biomedisa" (Lösel et al. (in press)). For the final models, Biomedisa's smoothed and filled segmentation results were chosen. The images of the 3D models presented in this study are screenshots of the surface models that were constructed as outlined above.

Phylogenetic analysis and taxon sampling

Peer) reviewing PDF | (2020:10:53763:1:1:ACCEPTED 19 Jan 2021) 
135 Phylogenetic analyses were carried out based on the character matrix of Darling (1996),

136

137

138

139

140

141

142

143

144

145

146

147

148

149

150

151

152

153

154

155

156

157

158

159

160

161

162

163

164

165

166

167

168

169

which comprises 24 morphological characters. The characters for the new fossils were scored and added. Character states of Spalangiopelta rameli Mitroiu, 2016 and Spalangiopelta viridis Mitroiu, 2016 were retrieved from literature and added as the respective species description allowed (Table 1). Altogether, the phylogenetic analysis in the present study includes 17 ingroup species (14 extant species and three fossil species), representing all known species of Spalangiopelta (Table 1). C. pulicaris was used as outgroup because of the morphological similarity and numerous shared characters with its sister genus Spalangiopelta. Character states were assigned to the respective Spalangiopelta species based on (re-)descriptions in the revision by Darling (1991) or the original descriptions (Darling 1995; Mitroiu 2016; Walker 1851).

Character 1: Hyaline break in parastigma. 0: absent, 1: present. The third character state ("partial") in Darling (1996) was removed, returning the character to a binary state. The partial hyaline break in $S$. georgei was assigned to state 1 because it is present regardless of its incompleteness.

Character 2: Length of ovipositor sheaths. 0: long, sheaths extended beyond apex of metasoma at least one-half length of hind tibia. 1: short, sheaths only slightly protruding, at most one-third length of hind tibia.

Character 3: Sculpture of midlobe of mesoscutum. 0: imbricate, 1: longitudinally striate, 2: transversely costulate, 3: alveolate. The third character state ("alveolate") was added to classify Spalangiopelta darlingi sp. $\mathrm{n}$. adequately.

Character 4: Length of petiole. 0: transverse, length about one-half maximum width, 1: campanulate, slightly longer than wide, 2 : elongate, length about twice maximum width, 3: subquadrate, 4: inconspicuous.

Character 5: Presence of short-winged females. 0: present, 1: absent. This character is classified as "present" in three species, Spalangiopelta felonia and Spalangiopelta brachyptera, as well as the outgroup C. pulicaris. In these species, some female specimens have wings so short that they do not reach the middle of the propodeum. It should be pointed out that both macropterous and brachypterous females are known in S. felonia and C. pulicaris, whereas in S. brachyptera all females have extremely reduced fore wings. Data were coded as "missing" for six species (Spalangiopelta alboaculeata, Spalangiopelta hiko, Spalangiopelta laevis and the fossil species Spalangiopelta georgei, Spalangiopelta darlingi sp. n. and Spalangiopelta semialba sp. n.) because as yet the number of specimens available is too low to assess with certainty if short-winged females are present in the six species in question. 
170

171

172

173

174

175

176

177

178

179

180

181

182

183

184

185 186

187

188

189

190

191

192

193

194

195

196

197

198

199

200

Character 6: Shape of hind margin of fore wing. 0: Fore and hind margins of fore wing parallel, 1: Fore wing margins not parallel, hind margin rounded, 2: Hind margin narrowed toward apex.

Character 7: Admarginal setae along the marginal vein. 0: present, 1: absent. The number of admarginal setae varies within individuals of the same species, therefore this character only codes for presence or absence of admarginal setae but not for the exact number of setae (Darling 1991).

Character 8: Shape of funicular segments of antenna. 0: funicular segments very long, length at least three times width, 1: quadrate, length subequal to width, 2: elongate, length about twice width, antenna overall slender with funicular segments cylindrical, 3: elongate, length about twice width, antenna overall robust with funicular segments widest in the middle, slightly barrel-shaped.

Character 9: Scape shape. 0: linear, cylindrical, 1: expanded, appears more robust. In the newly described fossil species, this character is reconstructible only through $\mu C T$ scans as the scape is hardly visible under the microscope.

Character 10: Sculpture of petiole. 0: with longitudinal costae, 1: alveolate without longitudinal costae, 2: smooth, without longitudinal costae.

Character 11: Size of metascutellum. 0: short, length much less than one-half length of mesoscutellum along midline. 1: long, about one-half length of mesoscutellum along midline, longer than frenum.

Character 12: Colour pattern of head. 0: concolourous with mesopleuron, 1: bicoloured, dark with white colouration on gena. Spalangiopelta semialba sp.n. is best described by character state 1 ("bicoloured") based on the bright colouration of the genal space. This bicoloured pattern does not seem to be an artefact of fossilisation due to the consistent presence on both sides of the head.

Character 13: Colour of fore coxa. 0: concolourous with mesopleuron, 1: white, strongly contrasted with mesopleuron.

Character 14: Sculpture of sub-median areas of propodeum. 0: imbricate, sculpture partly overlapping, appearing scaled, 1: finely areolate, divided into several small, irregular spaces, 2: alveolate, 3: glabrous, smooth, without any sculpture. 
201

202

203

204

205

206

207

208

209

210

211

212

213

214

215

216

217

218

219

220

221

222

223

224

225

226

227

228

229

230

231

232

233

234

235

Character 16: Angle of marginal and submarginal vein. 0: parallel, 1: angled. The outgroup C. pulicaris is the only species with character state 0 , therefore this character does not provide information on the relationships within the genus Spalangiopelta.

Character 17: Shape of fore wing. 0: narrow, length greater than 3.5 times width, 1 : wide, length less than 3.5 times width.

Character 18: Length of stigmal vein. 0: very short, almost sessile, 1: longer, about one-half length of postmarginal vein, $\mathrm{PM} / \mathrm{SV}=1.8-3.5,2$ : very long, almost as long as postmarginal vein, $\mathrm{PM} / \mathrm{SV}=1.3-1.5$.

Character 19: Angle of stigmal vein. 0: 45 degree angle with marginal and postmarginal veins, 1: 35 degree angle with marginal and postmarginal veins, 2: 25 degree angle with marginal and postmarginal veins. The angle of the stigmal vein with the marginal and postmarginal veins appeared slightly wider than 45 degrees in $S$. semialba sp.n., however due to the rather poor preservation of the wing venation and the resulting difficulty in measuring the angle accurately, it is classified as character state 0 (“45 degree”).

Character 20: Size of radicle. 0: very long, about one-third scape length. 1: short, only about one-tenth scape length, 2: robust, about one-fifth scape length, 3: long, about one-fourth scape length. The robust appearance of the radicle in $S$. albigena and $S$. laevis is likely due to their expanded, unusually robust scape (see Character 9 ).

Character 21: Configuration of notauli. 0 : distinct and linear, 1: shallow, broadly concave at scutellum, 2: shallow and indicated as broad pit-shaped depressions at mesoscutellum.

Character 22: Malar sulcus. 0: absent. 1: present (). Note that the malar sulcus is present in 15 species of Spalangiopelta, yet in the key to the subfamilies of Pteromalidae Graham (1969) lists "Malar sulcus absent" as one of the defining characters of Ceinae.

Mesquite version 3.61 (Maddison \& Maddison 2019) was used to assemble and modify the character matrix and for subsequent tree view and character tracing. Parsimony analyses were carried out in TNT version 1.5 (Goloboff et al. 2008; Goloboff \& Catalano 2016) with RAM usage set to 500 Mbytes and maximum space for 10,000 trees in memory. The small size of the data set allowed for the use of traditional search and implicit enumeration in TNT with C. pulicaris designated as outgroup. Traditional search was conducted with 100,000 replications and tree bisection reconnection (TBR) with 1000 trees saved per replication. Initially, all characters were unweighted. A strict consensus tree was calculated of the trees retained from traditional search and implicit 
236 enumeration. For implied weighting, a succession of concavity functions ranging from $\mathrm{k}$ $237=1$ to $\mathrm{k}=12$ were tested. Consistency indices and retention indices were calculated 238 with the TNT script "STATS". Bremer support was calculated using PAUP version 239 4.0a166 (Swofford 2003).

\section{Abbreviations}

241 The following abbreviations are used in the text:

$242 \quad$ A1-A3 $=$ anelli 1-3

243 C1-C3 = claval segment $1-3$

$244 \quad F 1-F 5=$ funicular segment $1-5$

$245 \mathrm{HH}=$ head height

246 HW $=$ Head width

$247 \mathrm{LOL}=$ lateral ocellar line

$248 \quad M S C=$ mesoscutum

$249 \mathrm{MSL}=$ mesoscutellum

$250 \mathrm{OOL}=$ ocular-ocellar line

$251 \mathrm{POL}=$ posterior ocellar line

$252 \quad \mathrm{PM}=$ postmarginal vein

253 SV = stigmal vein

$254 \quad \mathrm{~T} 1-\mathrm{T} 7=$ metasomal tergites $1-7$

255 SMNS = Staatliches Museum für Naturkunde Stuttgart/ State Museum of Natural History 256 Stuttgart

\section{LSID registration}

258 The electronic version of this article in Portable Document Format (PDF) will represent a 259 published work according to the International Commission on Zoological Nomenclature 260 (ICZN), and hence the new names contained in the electronic version are effectively 261 published under that Code from the electronic edition alone. This published work and 262 the nomenclatural acts it contains have been registered in ZooBank, the online 
263 registration system for the ICZN. The ZooBank LSIDs (Life Science Identifiers) can be 264 resolved and the associated information viewed through any standard web browser by 265 appending the LSID to the prefix http://zoobank.org/. The LSID for this publication is: 266 urn:Isid:zoobank.org:pub:F3A4D890-3480-41D2-B5A4-7C18E047C920. The online 267 version of this work is archived and available from the following digital repositories: 268 PeerJ, PubMed Central and CLOCKSS.

\section{Results}

270 Key to females of extant and fossil Spalangiopelta species

271

272

1. Ovipositor sheaths only slightly extended beyond apex of metasoma, protruded 273 distance less than 0.5 length of hind tibia

$274-$ Ovipositor sheaths distinctly extended beyond apex of metasoma, protruded

275 distance more than 0.5 length of hind tibia 8

276

2. Fore wing with transparent region ("hyaline break") in parastigma. Admarginal

277 setae below marginal vein absent.

- Fore wing without transparent region ("hyaline break") in parastigma. Admarginal setae below marginal vein present and large.

3. Notauli shallow and linear, broadly concave at mesoscutellum. Hind margin of fore wing parallel to fore margin. Length of metascutellum much less than half of mesoscutellum along midline.

S. canadensis Darling, 1991

283

284

285

286

287

288

289

290

291

292

- Notauli as broad, pit-like depressions. Fore wing rounded with hind margin not parallel to fore margin. Metascutellum longer than frenum, about half length of mesoscutellum along midline

S. alata Bouček, 1953

4. Funicular segments of antenna robustly elongate, length about 2 times width .....5

- Funicular segments of antenna subquadrate 6

5. Fore wing narrow, length greater than 3.4 times width. Sculpture of petiole alveolate S. viridis Mitroiu, 2016

- Fore wing wide, length 2.8 times maximum width. Petiole with longitudinal costae S. rameli Mitroiu, 2016

6. Malar sulcus distinct S. felonia Darling and Hanson, 1986 
293 - Malar sulcus absent

2947 7 First funicular segment quadrate, length subequal to width. Petiole transverse.

295 Ovipositor dark, not distinctly white

S. brachyptera Masi, 1922

296

- First funicular segment elongate, length about 1.5 width. Petiole subquadrate.

297

Ovipositor distinctly white

S. alboaculeata Darling, 1995

298

8. Wings completely hyaline, without any maculation. Known only from Baltic amber

299

300

- Wings with maculation, at least faintly infuscate marks

301

302

303

304

305

306

307

308

309

310

311

312

313

314

315

316

317

318

319

320

321

322

9. Midlobe of mesoscutum coarsely alveolate. Head concolourous, genae not strongly contrasted Spalangiopelta darlingi Moser sp. n. †

- Midlobe of mesoscutum superficially imbricate. Colour pattern of head bicoloured, brown with white colouration on genae (Fig. 4D)Spalangiopelta semialba Moser sp. n. $\dagger$

10. Fore wing narrow, length greater than 3.5 width

- Fore wing wide, length about 3 times maximum width.

11. Fore coxa white, strongly contrasted with mesopleuron

- Fore coxa brown to black, concolourous with mesopleuron

12. Petiole elongate, length about twice maximum width. Head concolourous. Hind margin of fore wing narrowed toward apex. Scape linear. Submedian areas of propodeum finely areolate. Malar sulcus absent

S. ciliata Yoshimoto, 1997

- Petiole inconspicuous. White colouration posterior of genae. Hind and fore margin of fore wing parallel, with asetose region along hind margin of fore wing. Scape expanded. Submedian areas of propodeum glabrous. Malar sulcus present and located posteriorly...

S. albigena Darling, 1991

13. Colour pattern of head bicoloured, brown with white colouration on genae. Fore wing with hyaline break in parastigma. Scape expanded. Funicular segments of antenna subquadrate. Stigmal vein angle $35^{\circ}$

S. laevis Darling, 1991

- Head concolourous, genae not strongly contrasted. Fore wing with admarginal setae. Scape linear. Stigmal vein angle $25^{\circ}$. Fossil known from Dominican amber

S. georgei † Darling, 1997 
14. Median carina on propodeum distinct

- Median carina on propodeum absent.

325

326

327

328

329

330

331

332

333

334

335

336

337

338

339

340

341

342

343

344

345

346

347

348

349

350

351
15. Petiole transverse, with longitudinal costae. Body colour dark blue-violet with iridescent reflections S. dudichi Erdös, 1955

- Petiole campanulate, slightly longer than wide, alveolate. Body colour iridescent blue-green

S. hiko Darling, 1995

16. Funicular segments subquadrate. Petiole transverse with longitudinal costae. Body colour blue-green S. apotherisma Darling and Hanson, 1986

- Funicular segments slenderly elongate, length about twice width. Petiole campanulate, slightly longer than wide, smooth. Body colour dark blue-violet with iridescent reflections

S. procera Graham, 1966

\section{Species description of Spalangiopelta darlingi Moser, sp. $\mathbf{n}$.}

(Fig. 1-3)

LSID: urn:Isid:zoobank.org:act:91C3491D-167E-438E-A336-36534722525D

Holotype: ㅇ, Eocene Baltic amber, collection number "SMNS BB-2851". Type repository: SMNS.

The specimen is located close to the edge of the amber piece. The left side of the specimen is well-preserved. On the right side, the metasoma is dented dorsally and therefore slightly deformed.

Exact provenance unknown. Specimen is from the Krylov collection, purchased by the SMNS in 2008.

Distribution: Known only from the holotype.

Etymology: The specific name is a patronym for D. Christopher Darling to honour his work on parasitoid Hymenoptera and without whose contributions the genus Spalangiopelta would lack half of its described species.

Diagnosis: Spalangiopelta darlingi is characterized by the distinct alveolate sculpture on the mesoscutum. It is the only species with the following combination of characters: long ovipositor sheaths (protruded beyond apex of metasoma more than 0.5 length of hind 
352 tibia), fore wing with six admarginal setae and no hyaline break, petiole transverse and

353

354

355

356

357

358

359

360

361

362

363

364

365

366

367

368

369

370

371

372

373

374

375

376

377

378

379

380

381

382

383

384

385

386 smooth (without longitudinal costae). Spalangiopelta darlingi is one of two known Eocene Spalangiopelta amber fossils. It can readily be distinguished from the other Baltic amber fossil S. semialba by the concolourous head and from the Dominican amber fossil S. georgei by the absence of a hyaline break in the anterior part of the marginal vein, the greater angle of the stigma vein with the anterior margin of the fore wing $\left(45^{\circ}\right.$ rather than $\left.25^{\circ}\right)$ and by the completely hyaline wings.

Description: Female. Length, about $0.75 \mathrm{~mm}$. Head concolourous dark brown with bluegreen iridescent reflections, antennae dark brown. Mesosoma, coxae and femora concolourous with head, hind tibia and tarsus slightly lighter. Fore wing long, extended beyond apex of metasoma 0.7 times body length, hyaline. Metasoma reddish-brown.

Head: In frontal view quadrate, $\mathrm{HW} / \mathrm{HH}: 1.0$. Sculpture of head weakly imbricate, except vertex finely reticulate. Black setae present along the parascrobal area and on the interorbital plane, vertex and ocular-ocellar areas devoid of pubescence. Malar sulcus distinct and located more posterior than in other species of Spalangiopelta, onethird eye height. OOL about $0.5 \mathrm{POL}$.

Antenna: radicle very short, 0.14 scape length. Scape slightly arched, linear. A3 elongate, slightly wider than long, longer than $A 1+A 2$. Length of $F 1$ shorter than width; F2-F5 subequal in length, slightly elongate, length 1.2 times width, segments conical. Clava elongate, subequal in length to F1-F5 combined, equal in length on dorsal and ventral surface. $\mathrm{C} 2$ widest claval segment.

Mesosoma: With imbricate sculpture, except lateral part of pronotum strigate, mesoscutum distinctly alveolate, upper mesepimeron alveolate, lower mesepimeron finely striate. Notauli distinct. Mesoscutellum shorter than mesoscutum, MSL/MSC about 0.7 . Frenum distinct. Metanotum about one-third MSL, distinctly longer than frenum. Propodeum extremely short, only about one-third length of mesoscutellum. Prepectus broadly triangular, with imbricate sculpture.

Fore wing: broad, length 2.6 times maximum width, about 0.7 times body length. Hind margin rounded. Apical setae rather short and dense, length 0.6 times stigmal vein, less than one-sixth maximum width of fore wing. With 6 admarginal setae. Parastigma without hyaline break. Basal vein distinctly pigmented. Submarginal vein 1.3 times marginal vein. Marginal vein of uniform thickness, length subequal to postmarginal. Postmarginal vein about twice stigmal, PM/SV $=2.1$. Stigmal vein slender and linear, making an angle of about 43 degrees with the postmarginal vein. Stigma significantly enlarged, uncus long with 3 or 4 sensilla.

Peer) reviewing PDF | (2020:10:53763:1:1:ACCEPTED 19 Jan 2021) 
387

388

389

390

391

392

393

394

395

396

397

398

399

400

401

402

403

404

405

406

407

408

409

410

411

412

413

414

415

416

417

Hind wing: narrow, length 6.4 times maximum width, with length of setae on apical and posterior margins 0.85 times width of hind wing.

Metasoma: Petiole transverse and rather inconspicuous. Gaster mostly shiny with fine reticulate sculpture on tergites, dark setae present laterally. T2 short, as long as T3-T4 combined. Laterotergite small, less than one-half height of gaster, with imbricate sculpture superficial. Ovipositor long, sheath extended distinctly beyond apex of metasoma, protruding from metasoma about 0.8 length of hind tibia. Length equal to $S$. apotherisma Darling and Hanson, 1986 (0.7) and the amber fossil S. georgei, the two known species with the longest ovipositor based on the ratio of the ovipositor sheaths' length and length of the hind tibia.

\section{Species description of Spalangiopelta semialba Moser, sp. $\mathbf{n}$.}

(Fig. 4-5)

LSID: urn:Isid:zoobank.org:act:10017E02-D18B-4731-94F6-3B5C2DBACE50

Holotype: , Eocene Baltic amber, collection number "SMNS BB-2852". Type repository: SMNS.

The specimen is close to the surface of the amber piece. An air bubble on the left side of the specimen obscures the left mesopleuron, the propodeum and the anterior half of the metasoma. The preservation of the wings is rather poor with wing venation and pilosity hardly visible, only setae on margins are visible. Aside from the wasp, the amber piece contains three syninclusions, two mites (Acari) and one female Ceratopogonidae (Diptera) (Fig. 6).

Exact provenance unknown. Specimen is from the Krylov collection, purchased by the SMNS in 2008.

Distribution: Known only from the holotype.

Etymology: The specific name refers to the bicoloured head with the strikingly bright genal space.

Diagnosis: Spalangiopelta semialba differs from all fossil and extant Spalangiopelta species by the combination of a distinct malar sulcus, an inconspicuous petiole, and a wide fore wing (length about 3.2 times width). It is one of two known Eocene Spalangiopelta amber fossils from Baltic amber and it differs from the other fossil 
418 species in having a bright genal space, giving the head a bicoloured colouration. It is the 419 smallest known species of Spalangiopelta with a body size of $0.55 \mathrm{~mm}$.

420 Description: Female. Length, about $0.55 \mathrm{~mm}$, slender in habitus. Head dark reddish421 brown with faint iridescent reflections, genal space brighter, antennae light brown. 422 Mesosoma concolorous dark reddish-brown with faint iridescent reflections, coxae and 423 femora brown, tarsi lighter. Fore wing long, extended beyond apex of metasoma 0.8 times body length, hyaline. Metasoma concolourous dark reddish-brown.

Head: In frontal view rectangular, $\mathrm{HW} / \mathrm{HH}: 0.5$. With very fine, superficially imbricate sculpture, except glabrous vertex and ocular-ocellar areas. Line of black setae present along the parascrobal area and along the posterior vertex, lower face devoid of pubescence. Malar sulcus distinct and very long, over half eye height, malar sulcus 0.6 eye height. OOL about $0.5 \mathrm{POL}$.

Antenna: Radicle very short, about 0.15 scape length. Scape narrowly linear. F1short, length 0.65 width, F2-F3 slightly broader than long, F4-F5 subquadrate. Clava extremely elongate, slightly longer than F1-F5 combined, segments almost cylindrical, equal in length on dorsal and ventral surface. $\mathrm{C} 1$ widest claval segment, wider than F14 , subequal in width to $\mathrm{F} 5$.

Mesosoma: With imbricate sculpture. Notauli distinct. Mesoscutellum shorter than mesoscutum, MSL/MSC about 0.9 . Frenum distinct (visible only in 3D reconstruction). Metanotum very long, about $0.6 \mathrm{MSL}$, about one-half length of mesoscutellum along midline, longer than frenum. Propodeum short, only about one-half length of MSL. Prepectus broadly triangular, with imbricate structure.

Fore wing: broad, length about 2.9 times maximum width, of intermediate length, extended to apex of metasoma, about 0.8 body length. Hind margin only slightly expanded. Apical setae sparse, as long as stigmal vein. Admarginal setae or hyaline break are not visible due to the poor state of preservation. Submarginal vein 1.7 times length of marginal vein. Marginal vein of uniform thickness, length subequal to postmarginal. Postmarginal vein long, $\mathrm{PM} / \mathrm{SV}=3.3$. Stigmal vein wide and straight, making an angle of about 55 degrees with the marginal and postmarginal vein. Stigma slightly enlarged, uncus long and broad, with 3 or 4 sensilla.

Hind wing: very narrow, length almost 9 times maximum width, with length of setae on apical and posterior margins subequal to width of hind wing. with scattered dark setae. T2 short, only as long as T3. Size and sculpture of laterotergite not clearly visible, thus not conclusively assessable. Ovipositor long, 
453 sheaths extended distinctly beyond apex of metasoma, protruded distance subequal to 454 length of hind tibia.

455

456

457

458

459

460

461

462

463

464

465

466

467

468

469

470

471

472

473

474

475

476

477

478

479

480

481

482

483

484

485

486

487

488

\section{Phylogenetic analysis}

In the unweighted phylogenetic analysis, both traditional search and implicit enumeration returned six trees that were equally parsimonious (length 58 , consistency index 0.655; retention index 0.71, Appendix C). In the strict consensus tree calculated from the equally parsimonious trees, the more distal species (i.e. S. albigena, S. laevis, S. canadensis, S. alata and S. georgei) are well-resolved, whereas the basal part of the tree is largely unresolved (Fig. 7). Spalangiopelta dudichi and S. apotherisma form a clade in the strict consensus tree. In all trees, $S$. laevis and $S$. albigena as well as $S$. canadensis and $S$. alata are returned as the two most distal sister clades. This cluster is well-supported as indicated by the high bootstrap values in the strict consensus tree.

The Dominican amber fossil S. georgei is returned as sister group to this well-supported distal clade. However, this placement is not well supported and it would also contrasts with the cladogram in Darling (1996), where S. georgei was returned as sister group to the most distal clade (S. albigena + S. laevis).

In the strict consensus tree, the Baltic amber fossil $S$. darlingi forms a polytomy with $S$. procera. Its exact placement is unresolved in that it is either returned as sister group to the S. ducichi + S. apotherima clade or as sister taxon to S. hiko. Spalangiopelta semialba, the other Baltic amber fossil, forms a polytomy with S. hiko.

Phylogenetic analyses using implied weighting with concavity constant values lower than $\mathrm{K}=4$ return multiple trees of length 59 or 60 , whereas concavity constant values higher than $\mathrm{K}=4$ produced three trees of length 58 . Therefore, the preferred tree topology presented here is the result of implied weighting of characters with a concavity constant of $\mathrm{K}=4$ (Fig. 8). Tree topology largely corresponds to the strict consenus (Fig. 7) but shows a better resolution along the base. Spalangiopelta ciliata is retrieved as sister group of the remaining Spalangiopelta species.

The implied weighting tree retained in this analysis largely corresponds to that of Darling (1996). However, there are three major differences in topology: (1) In the preferred tree topology of this study, S. ciliata constitutes the most basal species of Spalangiopelta. (2) S. felonia and S. brachyptera no longer cluster with S. alboaculeata as their sister group. Instead, they represent separate lineages. (3) The most distal part of the cladogram is represented by two synapomorphic clades, (S. albigena $+S$. laevis) and (S. alata + S. canadensis) with $S$. georgei as sister group to this most distal clade (Fig. 8).

Peer) reviewing PDF | (2020:10:53763:1:1:ACCEPTED 19 Jan 2021) 
490

491

492

493

494

495

496

497

498

499

500

501

502

503

504

505

506

507

508

509

510

511

512

513

514

515

516

517

518

519

520

521

522

523

524

525

The two Baltic amber fossils are closely related to each other and to the Western European S. procera as well as S. hiko, which has been found only in Japan (Fig. 8). The two new amber fossil species have little influence on the phylogeny. With $S$. darlingi and $S$. semialba removed from the phylogenetic analysis, topology changes only slightly. S. georgei becomes the sister group of the most distal clade of the two Caribbean species S. laevis + S. albigena, and S. apotherisma no longer forms a monophyletic clade with $S$. dudichi.

\section{Discussion}

\section{Character evolution and functional morphology of the mesopleuron in Spalangiopelta}

The distinct configuration of the hind margin of the mesopleuron, which is distinctly raised and partly covering the metapleuron, separates Spalangiopelta from the other genera in the subfamily Ceinae. This feature was hypothesized to facilitate flexible movement of the sclerites, thereby giving the mesosoma a more arched profile (Darling 1991). This character is present in both fossils, although it is more pronounced in $S$. darlingi. However, this character is not unique to the genus Spalangiopelta. In a comprehensive phylogenetic analysis of Chalcidoidea, this character was found in a range of taxa (character 111 "Mesepimeron relative to metapleural/propodeal complex" in Heraty et al. 2013). It was found in multiple species of Pteromalidae, Eulophidae, Eurytomidae and Tetracampidae and occasionally in Eriaporidae, Leucospidae and Perilampidae. Within the Pteromalidae examined by Heraty et al. (2013), this character is found in the subfamilies Cleonyminae, Leptofoeninae, Diparinae and Spalangiinae. Although these groups are morphologically distinct, a connection to forest habitats is common to many species within these subfamilies: The development of the majority of Cleonyminae and Leptofoeninae takes place inside wood (Vilhelmsen \& Turrisi 2011). Diparinae are associated with leaf litter on the forest floor (Desjardins 2007). Some Spalangiinae specimens were found in forest habitats (Gibson 2009). Therefore, it seems reasonable to acknowledge the hypothesis that Spalangiopelta females are associated with leaf litter habitats (Darling 1991). In addition, the wing reduction in females of $S$. brachyptera and the continuous variation in wing length reported in $S$. felonia, which have been found in large numbers in Berlese funnel extractions of the needle mat in a Douglas fir forest (Pseudotsuga menziesii (Mirb.) Franco (Pinaceae)), place these Spalangiopelta species into spatially restricted forest floor habitats (Darling \& Hanson 1986; Masi 1922). This reasoning is in line with the general rarity of Spalangiopelta specimens in collections. The presence of the raised mesopleuron in the 
526 newly described fossil species, as well as their overall morphological similarity to extant

527

528

529

530

531

532

533

534

535

536

537

538

539

540

541

542

543

544

545

546

547

548

549

550

551

552

553

554

555

556

557

558

559

560

561

species, suggest that these species might have lived in similar forest habitats 35 to 43 million years ago. Further, a wooded habitat would increase the chance for a specimen to turn into an amber fossil.

Within Pteromalidae, Macroglenes gramineus (Haliday 1833), Spalangia nigroaenea Curtis 1839 and Peckianus sp. Bouček 1975 also share the characteristic configuration of the mesopleuron that partly overlaps the metapleuron. Except for the Australian Collessina pachyneura Bouček 1975 and the monotypic genus Peckianus, which is known only from Canada and Brazil, all other species listed above are associated with various Dipteran families as hosts (Noyes 2019 and references therein).

\section{Character evolution and functional morphology of admarginal setae and the hyaline break in Spalangiopelta}

The most striking character that unites the distal species in this cladogram is the presence of an unpigmented spot in the parastigma of the fore wing termed "hyaline break", (character 1, Fig. 8). With the exception of $S$. alata, all distal species in the cladogram that possess a hyaline break in the fore wing are New World species. The presence or absence of a hyaline break and admarginal setae (character 7) within the genus Spalangiopelta has been a subject of discussion in other studies (Darling 1991, 1996). Every macropterous species of Spalangiopelta has either a hyaline break or admarginal setae close to the marginal vein on the underside of the fore wing. The only exceptions are S. ciliata, which has neither, and the Dominican amber fossil S. georgei, which has admarginal setae and a hyaline break (Darling 1996). Darling (1991) considers the absence of either character in $S$. ciliata the result of the regular aboveground activity of the species, which would explain why $S$. ciliata is found in Malaise traps regularly. Of the two fossils described herein, $S$. darlingi has six admarginal setae whereas in S. semialba, the state of preservation prevents the reconstruction of this character with certainty. From the pattern in the phylogeny it cannot be inferred whether S. semialba had admarginal setae, a hyaline break or both (Fig. 8). If S. semialba had admarginal setae, this would imply that the distal clade ((S. alata $+S$. canadensis) $+(S$. albigena $+S$. laevis)) share a common ancestor that lost admarginal setae and developed a hyaline break. This process might have occurred roughly 15 to 20 million years ago considering the age of the Dominican amber fossil $S$. georgei, which might represent a transitional stage (Darling 1996). If like in S. georgei admarginal setae and a hyaline break were present in the Baltic amber fossil $S$. semialba, the process of losing admarginal setae and developing a hyaline break could be dated back much further. 
562 Both wing characters have been suggested to help Spalangiopelta keep the wings

563 folded back to facilitate movement in restricted habitats such as leaf litter (Darling

564 1991). In a study that placed Ceinae as sister group of Diparinae, Desjardins (2007) 565 was able to observe "many diparine specimens [...] in which the setae appear to hold 566 the hind wing in place while they are folded against the body", thereby potentially 567 verifying the hypothesis proposed several years earlier. The author acknowledges that 568 the presence of admarginal setae in some species of Ceinae as well as Diparinae does 569 not necessarily denote relatedness but could indicate homoplasy based on the similarity 570 of the habitats of the hosts. The absence of admarginal setae in S. ciliata, which was 571 resolved as sister group to all other Spalangiopelta species in the phylogenetic analysis, 572 seems to confirm this view.

573 Based on the hypothesis that the hyaline break serves an identical purpose as the 574

575 admarginal setae, Darling (1991) considered these wing characters mutually exclusive.

576 However, there are several species of pteromalid wasps that share both wing characters, including C. pachyneura, M. gramineus, S. nigroaenea, Pteromalus albipennis Walker 1835 and an unidentified species of the genus Peckianus (characters

578

579 147 and 157 of Heraty et al. 2013). As both wing characters can be found not only in

580 females but also in males of Spalangiopelta, it appears that neither character is

581 associated directly with host location. Admarginal setae and a hyaline break do occur mutually in at least five species of Pteromalidae. The results of the phylogenetic

582 analysis presented here provide further evidence for the mutual presence of admarginal

583 setae and a hyaline break in S. georgei and potentially S. semialba. They contradict the

584 postulation by Darling (1991) that the mutual exclusivity is the result of identical

585 functions of both characters. As Darling (1991) stated, the hyaline break is "an example

586 of a fenestra or bulla, a weakened area of a vein that usually marks an area where a

587 fold or flexion line crosses the vein". Fenestrae occur where a flexion line crosses a

588 wing vein and are associated with complex changes of wing shape in flight (Danforth \&

589 Michener 1988; Wootton 1979). Therefore, we suggest that the hyaline break found in

590 the distal clade of Spalangiopelta presented here might be an adaptation to flying rather than to moving in confined habitats.

592

593

\section{Conclusions}

594

We add two new species to the fossil record of Chalcidoidea (Hymenoptera) from Baltic

595 amber and establish a minimum age of the genus Spalangiopelta of 35 to 43 million

596 years (upper Eocene). Further, we present a cladogram within which we place the

597 fossils based on the cladistic analysis of 22 morphological characters. The new

598 identification key to the genus includes all extant and fossil females of Spalangiopelta. 
599 The description is complemented by 3D models reconstructed from $\mu C T$ scans. The 600 models allow for a pivotable view and thus eliminate physical barriers such as refraction

601 or reflections that would otherwise obscure the view on specific parts of the inclusion

602 depending on the cut of the amber piece. Inclusions such as air bubbles or plant

603 particles that conceal potentially important structures of the specimen can also be

604 removed digitally. This method has proved an invaluable addition to classic techniques

605 in the description of amber fossils (Dierick et al. 2007; Faulwetter et al. 2013; van de

606 Kamp et al. 2018).

607 Coding additional morphological characters and including genetic data will further

608 improve the resolution of the phylogenetic analysis given here. Additional characters of

609 males could elucidate aspects of the phylogenetic placement that have yet remained

610 unclear such as the size of the metascutellum or the shape of the fore wing. To obtain

611 these characters, molecular data could be utilized to decisively match females with

612 males of Spalangiopelta. Increasing the number of Spalangiopelta specimens in

613 collections could prove productive to assess the range of absolute measurements in

614 certain characters within one species as well as to classify the variation in characters

615 such as wing length in S. felonia. This increase could be achieved by targeted

616 biodiversity assessments in promising habitats such as forest floors. In order to validate

617 any hypotheses regarding the functional morphology of prominent structures such as

618 the hyaline break, the admarginal setae and the raised mesopleuron, the observation of

619 live specimens could yield presently unknown insights into functional morphology,

620 behaviour and host range of the genus Spalangiopelta.

621

\section{Acknowledgements}

623 We thank Tanja Schweizer (SMNS) for technical assistance in the preparation of the 624 amber pieces. We would also like to show our gratitude to Michael Haas and Milan

625 Pallmann (both SMNS) for support in operating imaging hardware and software. We 626 thank Marcus Zuber and Tomás Faragó (both KIT) for their assistance during the 627 tomographic experiment. We acknowledge the KIT light source for provision of 628 instruments at their beamlines and we would like to thank the Institute for Beam Physics 629 and Technology (IBPT) for the operation of the storage ring, the Karlsruhe Research 630 Accelerator (KARA). We thank André Nel, Mircea-Dan Mitroiu and one anonymous 631 reviewer for their time and effort in helping to improve an earlier version of this 632 manuscript. 


\section{References}

635 Bouček, Z. (1961): Beiträge zur Kenntnis der Pteromaliden-fauna von Mitteleuropa mit 636 Beschreibungen neuer Arten und Gattungen (Hymenoptera). In Acta Entomologica 637 Musei Nationalis Pragae 34.

638 Burleigh, R.; Whalley, P. (1983): On the relative geological ages of amber and copal. In 639 Journal of Natural History 17 (6), pp. 919-921. DOI: 10.1080/00222938300770721.

640 Cecilia, A.; Rack, A.; Douissard, P.-A.; Martin, T.; dos Santos Rolo, T.; Vagovič, P.; 641 Hamann, E.; van de Kamp, T.; Riedel, A.; Fiederle, M.; Baumbach, T. (2011): LPE 642 grown LSO:Tb scintillator films for high-resolution X-ray imaging applications at 643 synchrotron light sources. In Nuclear Instruments and Methods in Physics Research 644 Section A: Accelerators, Spectrometers, Detectors and Associated Equipment 648, 645 S321-S323. DOI: 10.1016/j.nima.2010.10.150.

646 Danforth, B.N.; Michener, C.D. (1988): Wing Folding in the Hymenoptera. In Annals of 647 the Entomological Society of America 81 (2), pp. 342-349. DOI: 10.1093/aesa/81.2.342.

648 Darling, D.C. (1991): Revision of the world species of Spalangiopelta (Hymenoptera:

649 Chalcidoidea: Pteromalidae: Ceinae). Toronto: Royal Ontario Museum.

650 Darling, D.C. (1995): New Palearctic Species of Spalangiopelta (Hymenoptera:

651 Chalcidoidea: Pteromalidae: Ceinae). In Canadian Entomologist 127 (2), pp. 225-233.

652 DOI: 10.4039/Ent127225-2.

653 Darling, D.C. (1996): A New Species of Spalangiopelta (Hymenoptera; Pteromalidae; 654 Ceinae) from Dominican Amber: Phylogenetic and Biogeographic Implications. In 655 Journal of the Kansas Entomological Society 69 (4), pp. 248-259.

656 Darling, D.C.; Hanson, P. E. (1986): Two new species of Spalangiopelta from Oregon 657 (Hymenoptera: Chalcidoidea), with a discussion of wing length variation. In The Pan658 Pacific entomologist 62 (2) pp. 153-164

659 Desjardins, C.A. (2007): Phylogenetics and classification of the world genera of 660 Diparinae (Hymenoptera: Pteromalidae). In Zootaxa 1647 (1), pp. 1-88. DOI: 661 10.11646/zootaxa.1647.1.1.

662 Desjardins, C.A.; Regier, J.C.; Mitter, C. (2007): Phylogeny of pteromalid parasitic 663 wasps (Hymenoptera: Pteromalidae): initial evidence from four protein-coding nuclear 664 genes. In Molecular phylogenetics and evolution 45 (2), pp. 454-469. DOI:

665 10.1016/j.ympev.2007.08.004.

666 Dierick, M.; Cnudde, V.; Masschaele, B.; Vlassenbroeck, J.; van Hoorebeke, L.; Jacobs, 667 P. (2007): Micro-CT of fossils preserved in amber. In Nuclear Instruments and Methods 
668 in Physics Research Section A: Accelerators, Spectrometers, Detectors and Associated 669 Equipment 580 (1), pp. 641-643. DOI: 10.1016/j.nima.2007.05.030.

670 Faulwetter, S.; Vasileiadou, A.; Kouratoras, M.; Thanos, D.; Arvanitidis, C. (2013):

671 Micro-computed tomography: Introducing new dimensions to taxonomy. In ZooKeys 672 (263), pp. 1-45. DOI: 10.3897/zookeys.263.4261.

673 Gibson, G.A.P. (2009): Revision of New World Spalangiinae (Hymenoptera:

674 Pteromalidae). In Zootaxa 2259 (1), pp. 1-159.

675 Goloboff, P.A.; Farris, J.S.; Nixon, K.C. (2008): TNT, a free program for phylogenetic 676 analysis. In Cladistics 24 (5), pp. 774-786. DOI: 10.1111/j.1096-0031.2008.00217.x.

677 Goloboff, P.A.; Catalano, S.A. (2016): TNT version 1.5, including a full implementation 678 of phylogenetic morphometrics. In Cladistics 32 (3), pp. 221-238. DOI:

679 10.1111/cla.12160.

680 Graham, M.W.R.d.V. (1969): The Pteromalidae of North-Western Europe 681 (Hymenoptera: Chalcidoidea). London: Bulletin of the British museum (Natural history) 682 entomology.

683 Grimaldi, D.A. (1995): The Age of Dominican Amber. In Anderson, K.B.; Crelling, J.C. 684 (Eds.): Amber, Resinite, and Fossil Resins, vol. 617. Washington, DC: American 685 Chemical Society (ACS symposium series), pp. 203-217.

686 Grimaldi, D.A. (1996): Amber. Window to the past. New York, London: Harry N. 687 Abrams.

Harris, R. (1979): A glossary of surface sculpturing. California Department of Food and 690 Agriculture, Bureau of Entomology. In Occasional Papers in Entomology, California Dept. of Food and Agriculture 28, pp. 1-31.

Heraty, J.M.; Burks, R.A.; Cruaud, A.; Gibson, G.A.P.; Liljeblad, J.; Munro, J.; Rasplus, J.Y.; Delvare, G.; Janšta, P.; Gumovsky, A.; Juber, J.; Woolley, J.B.; Krogmann, L.; Heydon, S.; Polaszek, A.; Schmidt, S.; Darling, D.C.; Gates, M.W.; Mottern, J.; Murray, 694 E.; Molin, A.D.; Triapitsyn, S.; Baur, H.; Pinto, J.D.; van Noort, S.; George, J.; Yoder, M. (2013): A phylogenetic analysis of the megadiverse Chalcidoidea (Hymenoptera). In 696 Cladistics 29 (5), pp. 466-542. DOI: 10.1111/cla.12006.

697 Iturralde-Vinent, M.A. (2001): Geology of the amber-bearing deposits of the Greater 698

699 Iturralde-Vinent, M.A.; MacPhee, R. D. E. (1996): Age and Paleogeographical Origin of 700 Dominican Amber. In Science 273 (5283), pp. 1850-1852. DOI:

701 10.1126/science.273.5283.1850. 
702 Langenheim, J.H. (2003): Plant resins. Chemistry, evolution, ecology, and ethnobotany. 703 Portland, Timber Press.

704 Lösel, P.; van de Kamp, T.; Jayme, A.; Ershov, A.; Faragó, T.; Tan Jerome, N.; Aedepu, 705 N.; Bremer, S.; Chilingaryan, S.A.; Heethoff, M.; Kopmann, A.; Odar, J.; Schmelzle, S.; 706 Zuber, M.; Wittbrodt, J.; Baumbach, T.; Heuveline, V. (2020): Introducing Biomedisa as 707 an open-source online platform for biomedical image segmentation. In Nature 708 Communications 11 (5577), DOI: 10.1038/s41467-020-19303-w.

709 Maddison, W.P. \& Maddison, D.R. (2019): Mesquite: a modular system for evolutionary 710 analysis. Version 3.61. http://www.mesquiteproject.org.

711 Mitroiu, M.-D. (2016): Review of world genera of Ceinae, with the description of two new 712 Palaearctic species of Spalangiopelta Masi (Hymenoptera, Chalcidoidea,

713 Pteromalidae). In European Journal of Tayonomy (251). DOI: 10.5852/ejt.2016.251.

714 Noyes, J.S. (2019): Universal Chalcidoidea Database. World Wide Web electronic 715 publication. http://www.nhm.ac.uk/chalcidoids (last accessed on 19 April 2020).

716 Poinar, G.O. (1992): Life in amber. Stanford: Stanford University Press.

717 Ritzkowski, S. (1997): K-Ar-Altersbestimmungen der bernsteinführenden Sedimente des 718 Samlandes (Paläogen, Bezirk Kaliningrad). Metalla, Sonderheft 66 zum Symposium 719 Neue Erkenntnisse zum Bernstein. In Metalla 66 (Sonderheft).

720 Ruthensteiner, B.; Hess, M. (2008): Embedding 3D models of biological specimens in 721 PDF publications. In Microscopy research and technique 71 (11), pp. 778-786. DOI: 722 10.1002/jemt.20618.

723 Sadowski, E.-M.; Schmidt, A.R.; Seyfullah, L.J.; Kunzmann, L. (2017): Conifers of the 724 "Baltic Amber Forest" and Their Palaeoecological Significance. In Stapfia (106), pp. 172573.

726 Standke, G. (2008): Bitterfelder Bernstein gleich Baltischer Bernstein? Eine geologische 727 Raum-Zeit-Betrachtung und genetische Schlußfolgerungen. In Rascher J. (Ed.):

728 Bitterfelder Bernstein versus baltischer Bernstein - Hypothesen, Fakten, Fragen. II. 729 Bitterfelder Bernsteinkolloquium; Tagungspublikation zum 24. Treffen des 730 Arbeitskreises Bergbaufolgen der Deutschen Gesellschaft für Geowissenschaften 25. 731 27. September 2008 in Bitterfeld. Duderstadt: Mecke (Exkursionsführer und 732 Veröffentlichungen der Deutschen Gesellschaft für Geowissenschaften, 236), pp. 1173333.

734 Swofford, D.L. (2003): PAUP*. Phylogenetic Analysis Using Parsimony (*and Other 735 Methods). Version 4. Sinauer Associates, Sunderland, Massachusetts. 
736 van de Kamp, T.; Schwermann, A.; dos Santos Rolo, R.; Lösel, R.D.; Engler, R.; Etter, 737 W.; Faragó, T.; Göttlicher, J.; Heuveline, V.; Kopmann, A.; Mähler, B.; Mörs, T.; Odar, 738 J.; Rust, J.; Jerome, N.T.; Vogelgesang, M.; Baumbach, T.; Krogmann, L. (2018):

739 Parasitoid biology preserved in mineralized fossils. In Nature communications 9 (1), p.

740 3325. DOI: 10.1038/s41467-018-05654-y.

741 Vilhelmsen, L.; Turrisi, G.F. (2011): Per arborem ad astra: morphological adaptations to 742 exploiting the woody habitat in the early evolution of Hymenoptera. In Arthropod

743 structure \& development 40 (1), pp. 2-20. DOI: 10.1016/j.asd.2010.10.001.

744 Vogelgesang, M., Chilingaryan, S., dos Santos Rolo, T. \& Kopmann, A. (2012): UFO: a 745 scalable GPU-based image processing framework for on-line monitoring. Proc. HPCC746 ICESS, pp. 824-829.

747 Walker, F. (1851): Notes on Chalcidites, and descriptions of various new species. In 748 Taylor, R. (Ed.): The Annals and magazine of natural history; zoology, botany, and 749 geology: London, Taylor and Francis, Ltd, pp. 210-217.

750 Wootton, R. J. (1979): Function, homology and terminology in insect wings. In 751 Systematic Entomology 4 (1), pp. 81-93. DOI: 10.1111/j.1365-3113.1979.tb00614.x.

752 Yoder, M. J.; Mikó, I.; Seltmann, K. C.; Bertone, M. A.; Deans, A. R. (2010): A gross 753 anatomy ontology for Hymenoptera. In PloS one 5 (12), e15991. DOI:

754 10.1371/journal.pone.0015991. 
Figure 1

Habitus drawing of Spalangiopelta darlingi sp. n., holotype, female.

Lateral left side. 


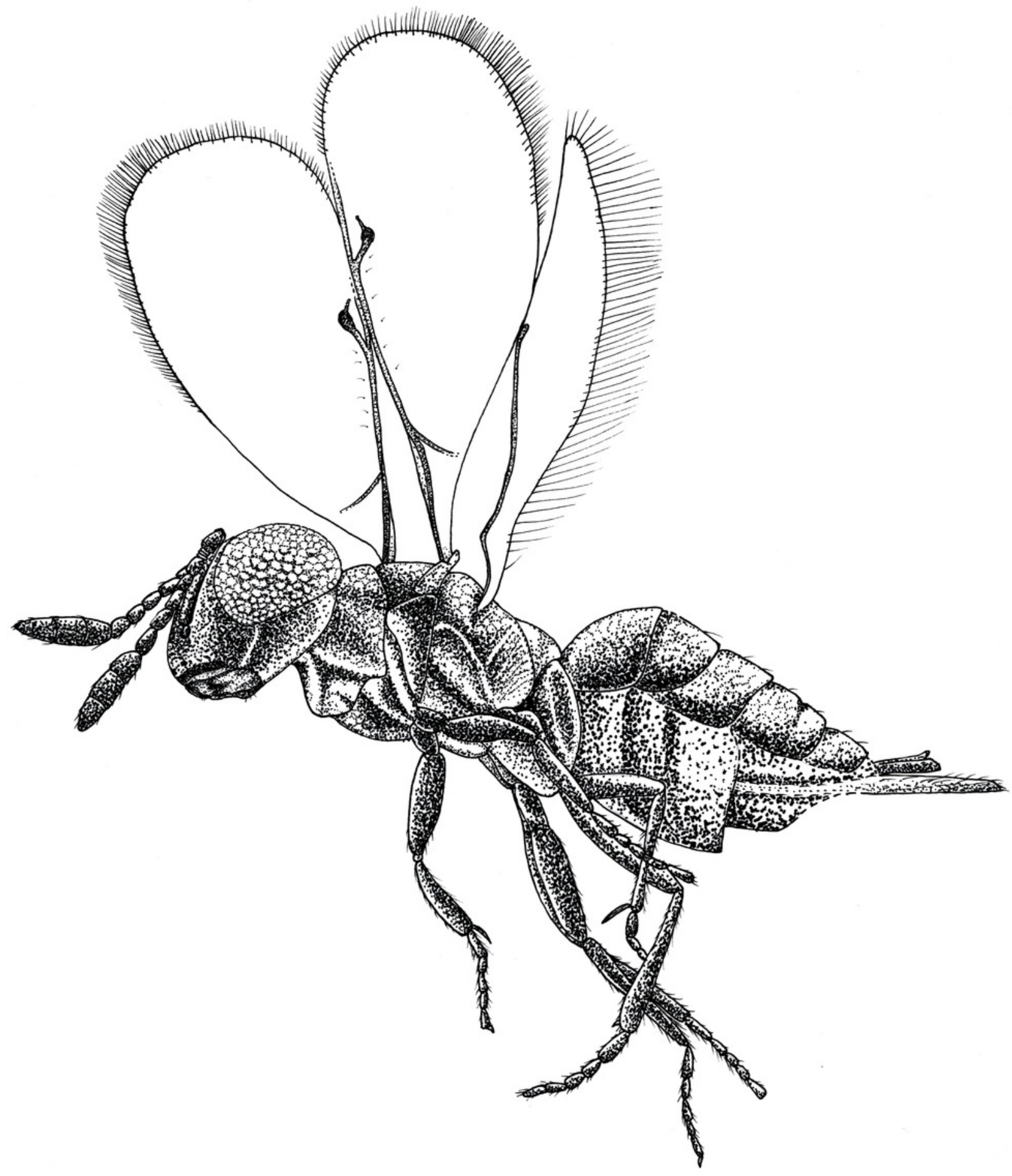


Figure 2

Spalangiopelta darlingi sp. n., holotype, female.

A. Lateral habitus of the left side. B. Lateral habitus of the right side. C. Detail image of wings. D. Detail image of head with antennae.

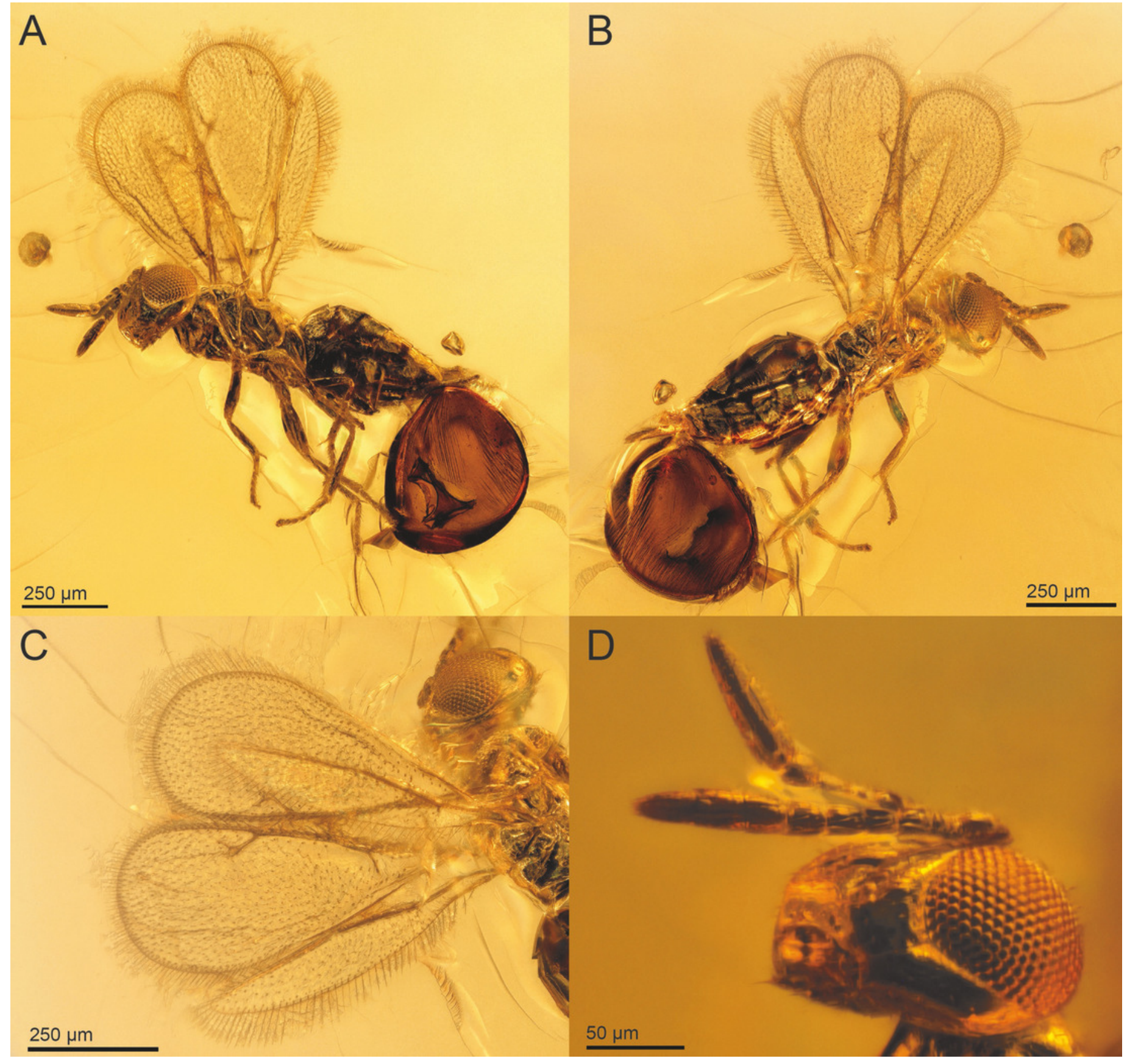




\section{Figure 3}

Digital surface models of 3D reconstruction of Spalangiopelta darlingi sp. n., holotype, female.

A. Lateral habitus of the left side. B. Lateral habitus of the right side. C. Detail view of head and antennae. D. Dorsal view of metasoma.
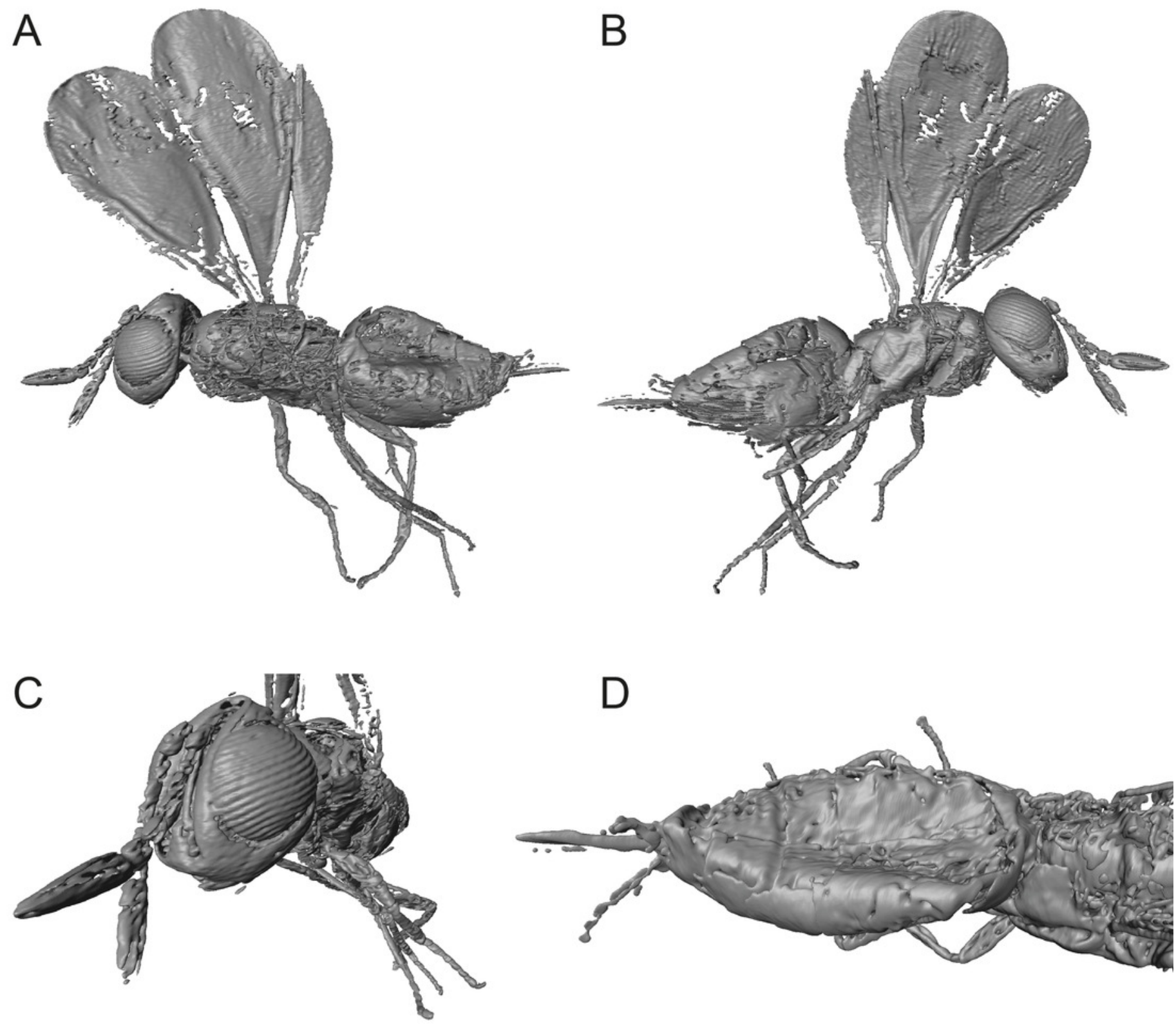
Figure 4

Spalangiopelta semialba sp. n., holotype, female.

A. Lateral habitus of the left side. B. Lateral habitus of the right side. C. Detail image of wings. D. Detail image of head with antennae. 


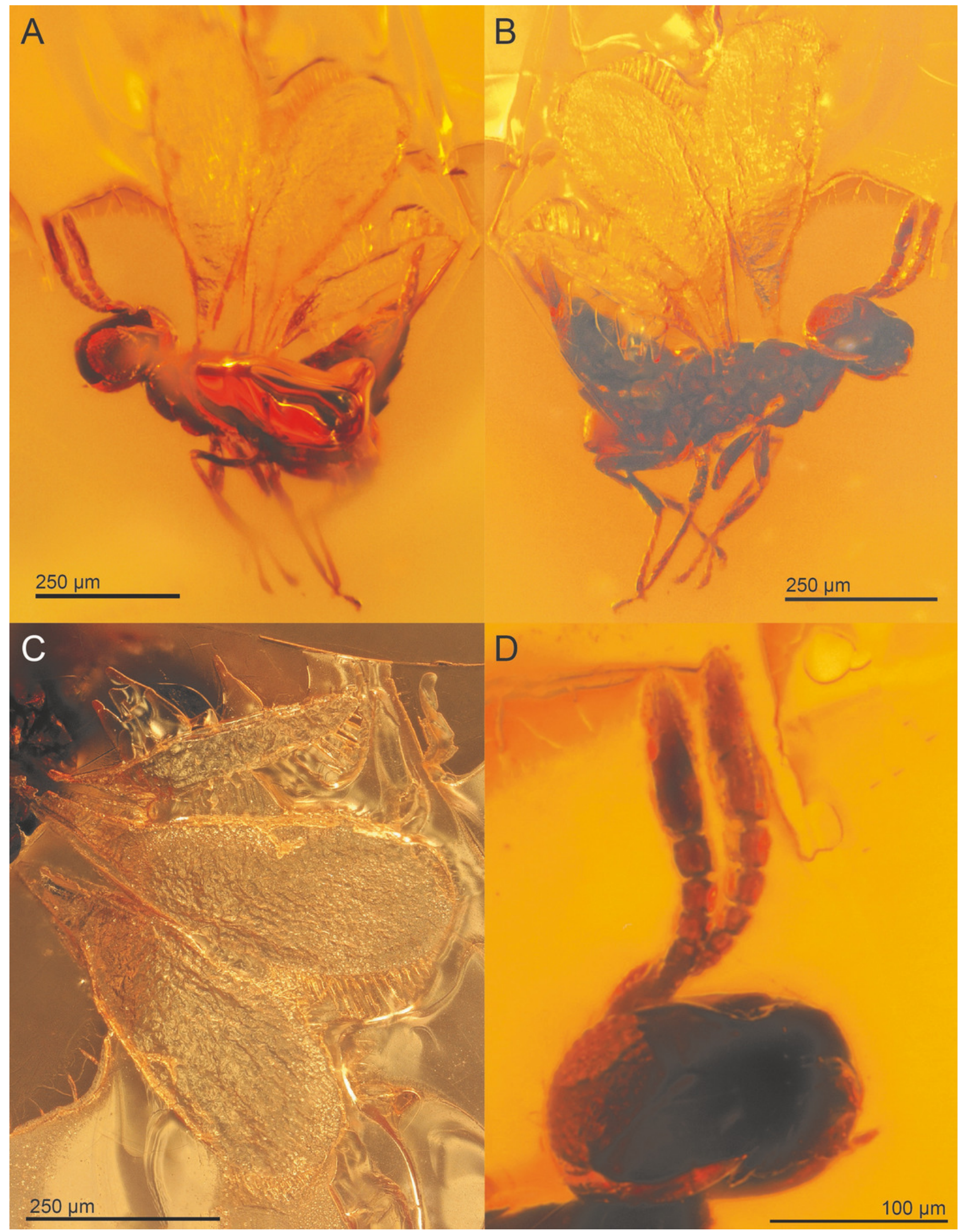


Figure 5

Digital surface models of 3D reconstruction of Spalangiopelta semialba sp. n., holotype, female.

A. Lateral habitus of the right side. B. Lateral habitus of the left side. C. Detail view of head and antennae. D. Dorsal view of posterior mesosoma and metasoma. 

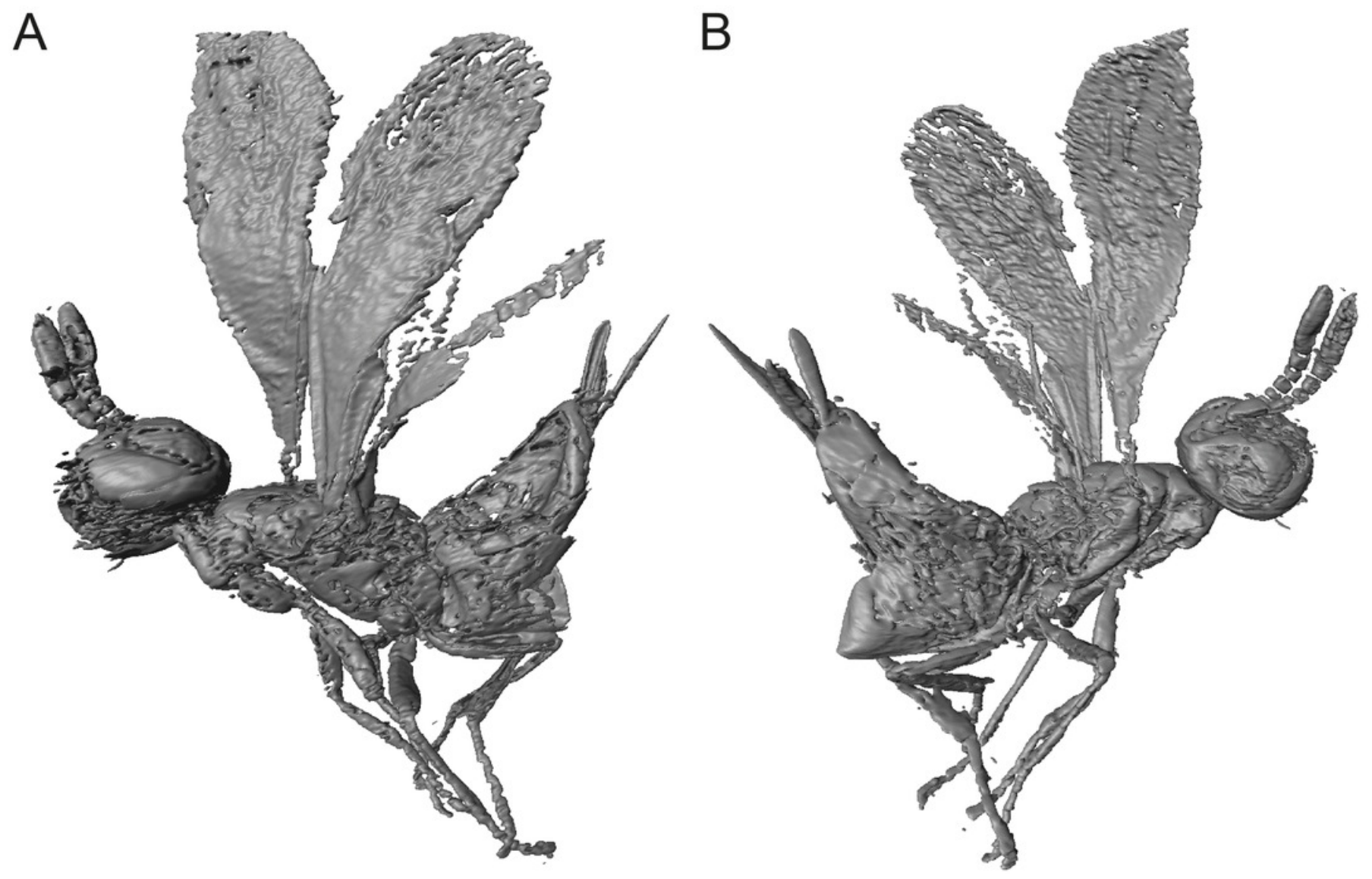

C
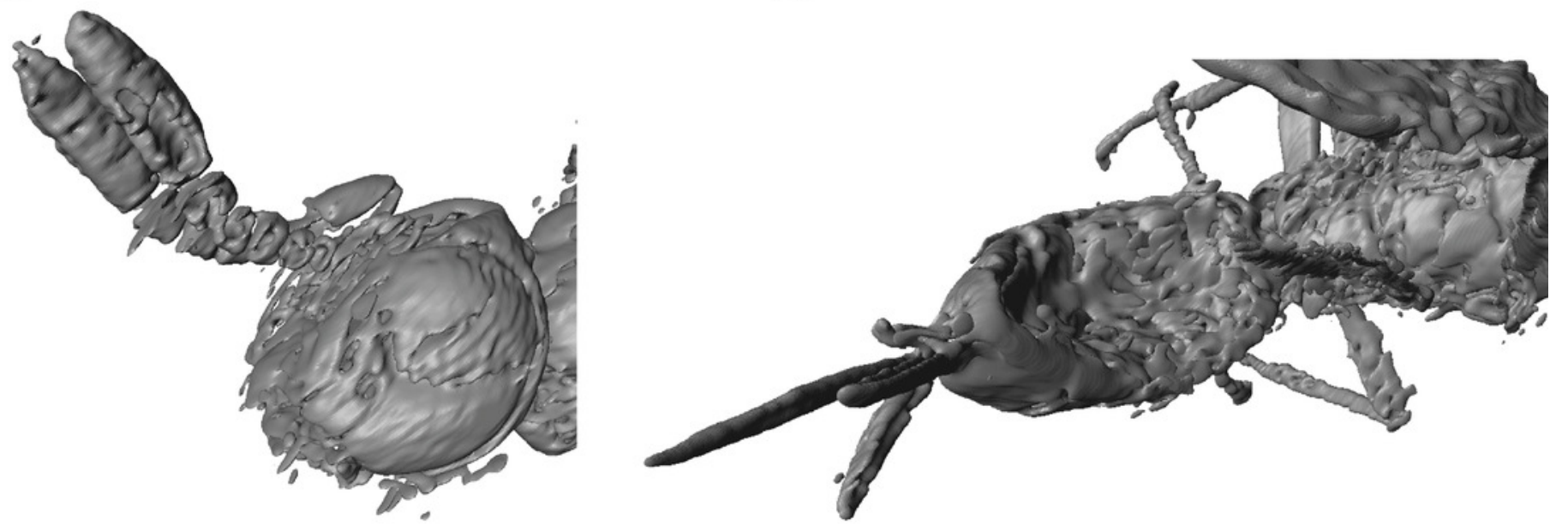
Figure 6

Syn-inclusions of Spalangiopelta semialba sp. n. in the amber piece "SMNS BB2852".

A. Ceratopogonidae (Diptera). B. Acari.

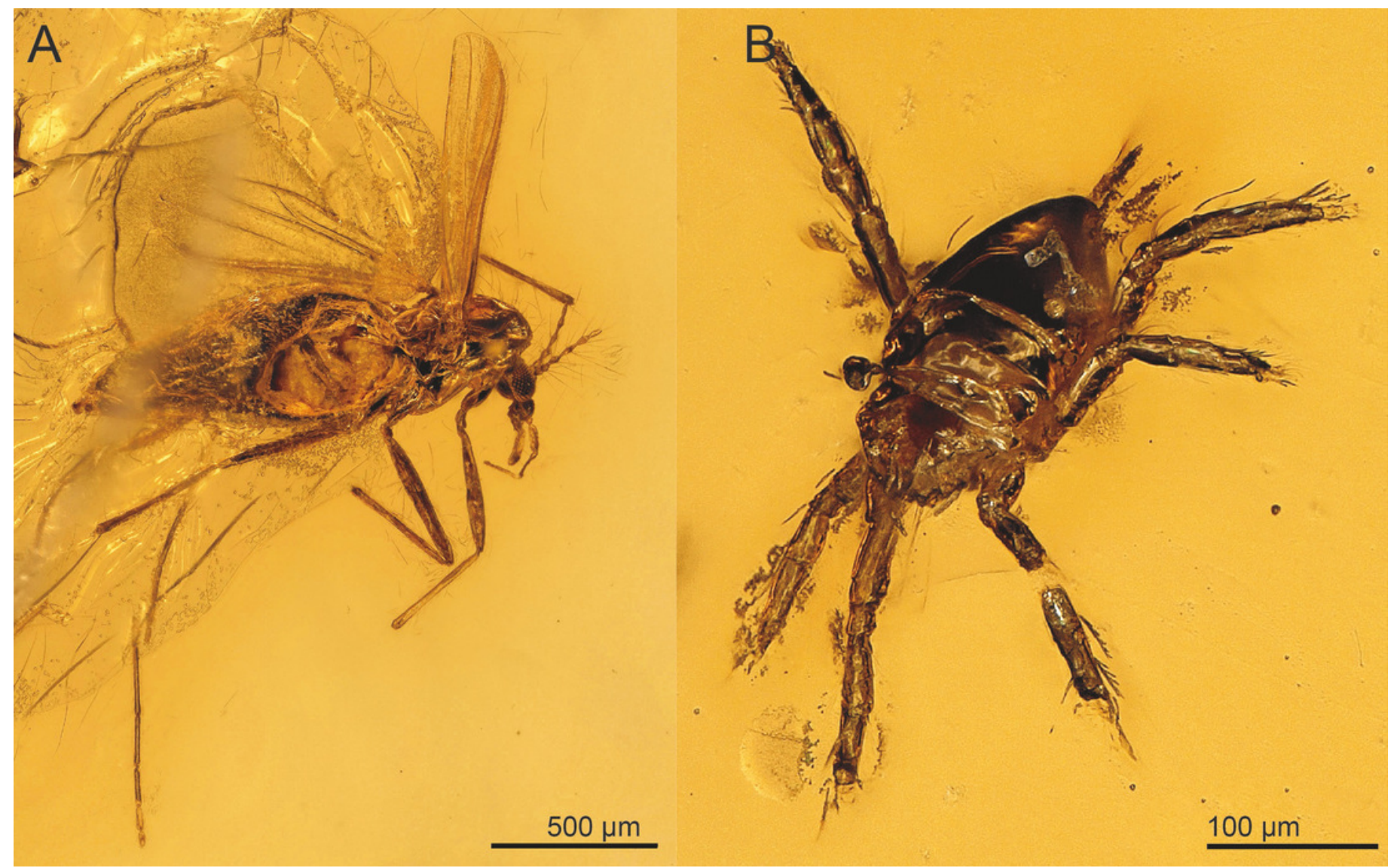




\section{Figure 7}

Equal weighting tree showing phylogenetic relationships between exant and fossil Spalangiopelta species based on female morphological characters.

Strict consensus calculated from 6 trees (length 58, consistency index 0.655; retention index $0.71,18$ taxa, 22 characters). Only bootstrap values over 70 are shown. Bootstrap values represent absolute frequencies based on 1000 replicates. 


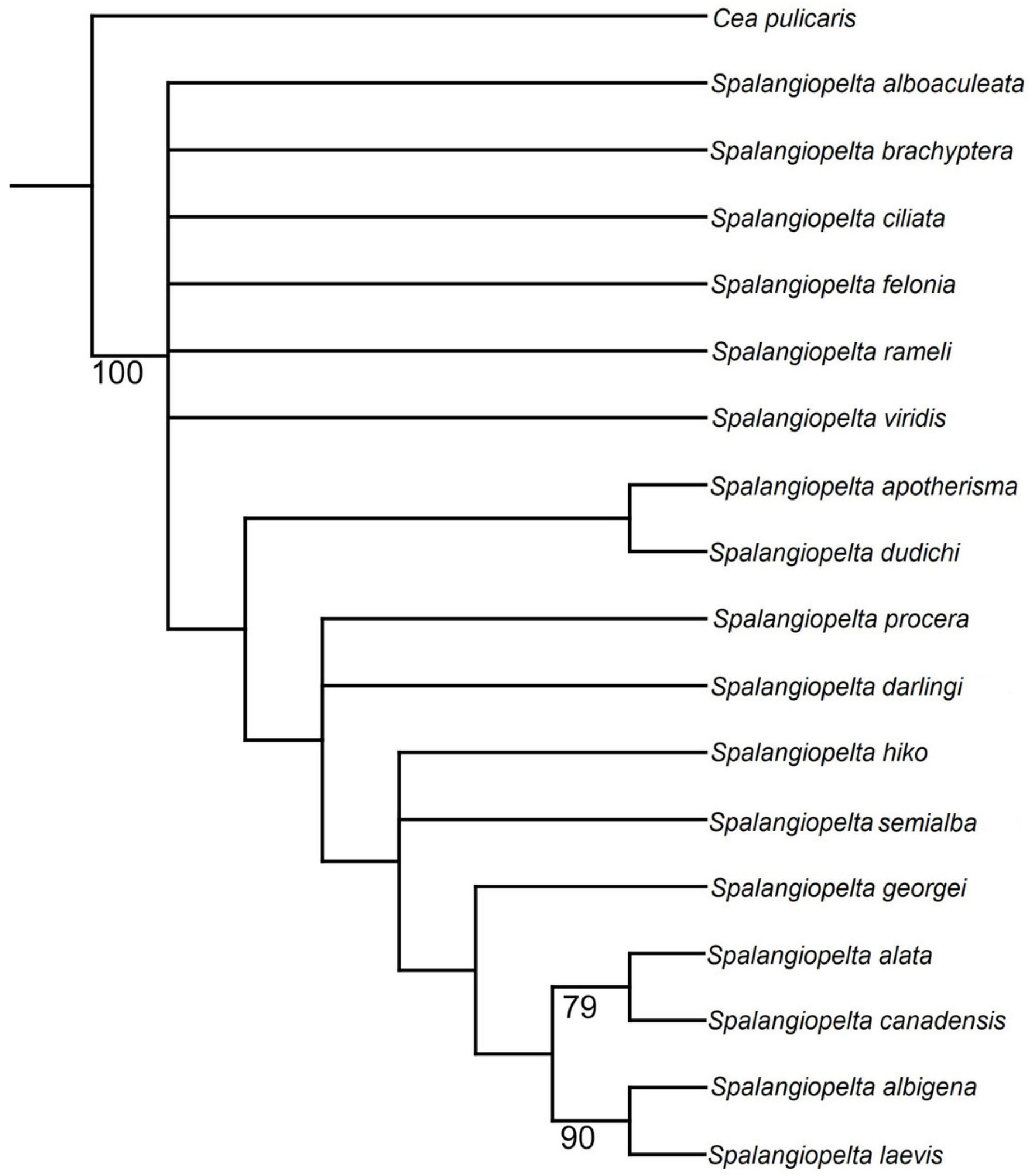


Figure 8

Implied weighting tree $(\mathrm{k}=4)$ showing phylogenetic relationships between exant and fossil Spalangiopelta species based on female morphological characters.

Tree length 58, 18 taxa, 22 characters. Resolution of the tree is based on implied weighting. Asterisks (*) annotate New World species. Insets map the distribution of admarginal setae (above) and hyaline break (below). 


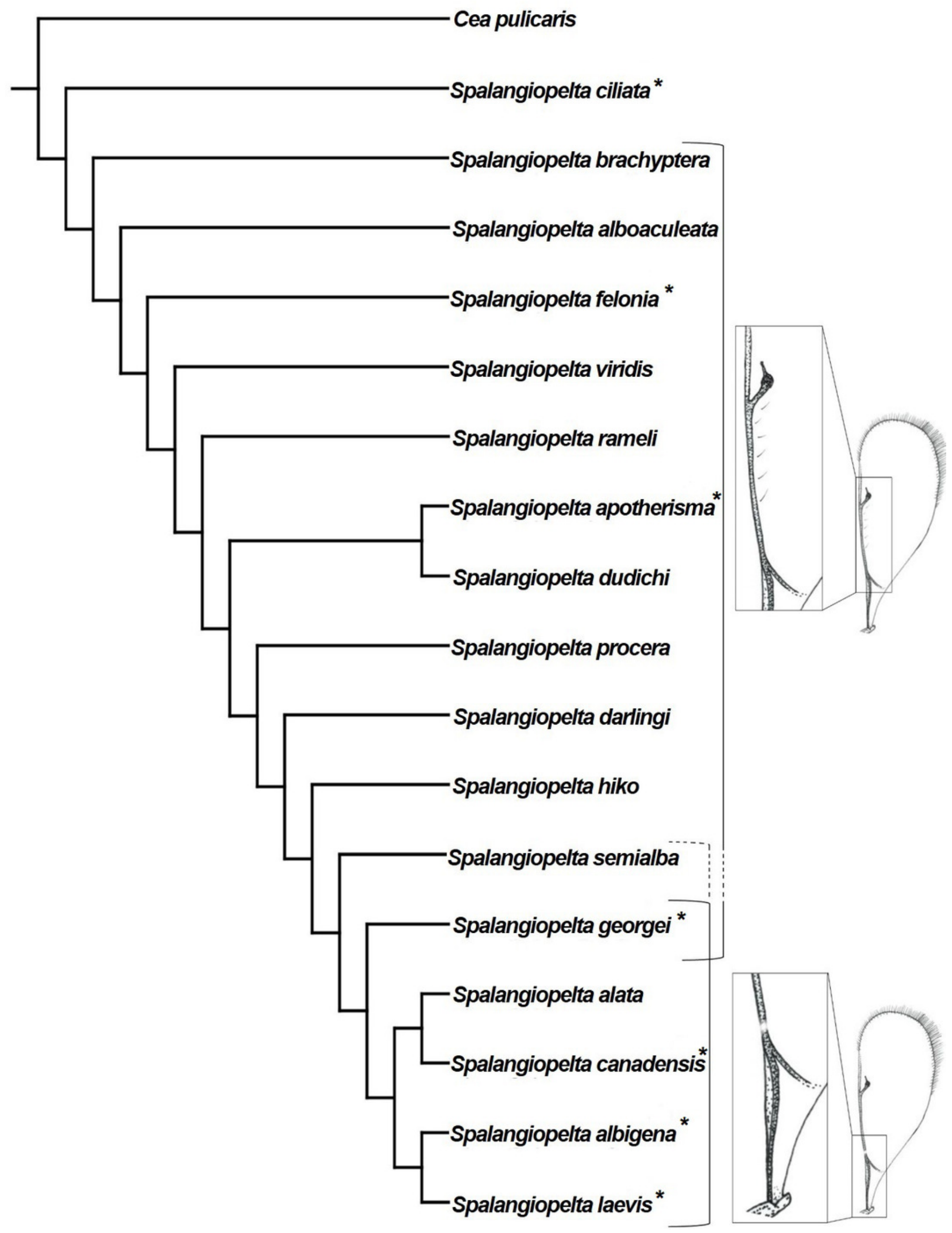




\section{Table $\mathbf{1}$ (on next page)}

Data matrix for Spalangiopelta females and the outgroup Cea pulicaris.

$0=$ ancestral state, $1,2,3,4=$ derived states. ? = missing data, $-=$ gaps. See text and Darling (1996) for description of characters and states. 


\begin{tabular}{lllllllllllll}
\hline Character & 1 & 2 & 3 & 4 & 5 & 6 & 7 & 8 & 9 & 10 & 11 & 12 \\
\hline Character number & 1 & 2 & 3 & 4 & 7 & 8 & 9 & 10 & 11 & 12 & 13 & 14
\end{tabular}

1 in Darling (1996)

\begin{tabular}{lllllllllllll}
\hline Cea pulicaris & 0 & 0 & 0 & 0 & 0 & 0 & 0 & 0 & 0 & 0 & 0 & 0 \\
S. alata & 1 & 1 & 0 & 1 & 1 & 1 & 1 & 3 & 0 & 1 & 1 & 0 \\
S. albigena & 1 & 0 & 2 & 4 & 1 & 0 & 1 & 1 & 1 & 2 & 1 & 1 \\
S. alboaculeata & 0 & 1 & 0 & 3 & $?$ & 0 & 0 & 1 & 0 & 0 & 0 & 0 \\
S. apotherisma & 0 & 0 & 0 & 0 & 1 & 1 & 0 & 1 & 0 & 0 & 0 & 0 \\
S. brachyptera & 0 & 1 & 0 & 0 & 0 & - & 0 & 1 & 0 & 0 & 0 & 0 \\
S. canadensis & 1 & 1 & 0 & 1 & 1 & 0 & 1 & 3 & 0 & 1 & 1 & 0 \\
S. ciliata & 0 & 0 & 1 & 2 & 1 & 2 & 1 & 1 & 0 & 0 & 0 & 0 \\
S. dudichi & 0 & 0 & 0 & 0 & 1 & 1 & 0 & 1 & 0 & 0 & 0 & 0 \\
S. felonia & 0 & 1 & 0 & 0 & 0 & 1 & 0 & 1 & 0 & 0 & 0 & 0 \\
S. georgei & 1 & 0 & 0 & 4 & $?$ & 1 & 0 & 2 & 0 & 2 & 1 & 0 \\
S. hiko & 0 & 0 & 0 & 1 & 1 & 1 & 0 & 1 & 0 & 1 & 1 & 0 \\
S. laevis & 1 & 0 & 0 & 4 & $?$ & 0 & 1 & 1 & 1 & 2 & 1 & 1 \\
S. procera & 0 & 0 & 0 & 1 & $?$ & 1 & 0 & 2 & 0 & 2 & 0 & 0 \\
S. rameli & 0 & 1 & 0 & 0 & 1 & 1 & 0 & 2 & 0 & 0 & 0 & 0 \\
S. viridis & 0 & 1 & 0 & 0 & 1 & 1 & 0 & 1 & 0 & 1 & 0 & 0 \\
S. darlingi sp. n. & 0 & 0 & 3 & 0 & $?$ & 1 & 0 & 1 & 0 & 2 & 1 & 0 \\
S. semialba sp. n. & $?$ & 0 & 0 & 4 & $?$ & 1 & $?$ & 1 & 0 & $?$ & 1 & 1 \\
\hline
\end{tabular}




\section{Table 2 (on next page)}

Amira measurements of structures of Spalangiopelta darlingi sp. n. and Spalangiopelta semialba sp. n., holotypes.

All measurements are in $\mu \mathrm{m}$. 


\begin{tabular}{|c|c|c|}
\hline Measurement & $\begin{array}{l}\text { Spalangiopelta } \\
\text { darlingi sp. } \mathrm{n} .\end{array}$ & $\begin{array}{l}\text { Spalangiopelta } \\
\text { semialba } \text { sp. n. }\end{array}$ \\
\hline Total body length & 742 & 550 \\
\hline Length of head & 116 & 103 \\
\hline Length of mesosoma & 253 & 231 \\
\hline Length of metasoma & 342 & 220 \\
\hline $\mathrm{T} 2$ & 77 & 26 \\
\hline T3 & 21 & 28 \\
\hline T4 & 53 & 26 \\
\hline T5 & 64 & 30 \\
\hline T6 & 71 & 42 \\
\hline $\mathrm{T} 7$ & 55 & 48 \\
\hline $\mathrm{T} 8$ & 35 & 21 \\
\hline Ovipositor sheath length & 134 & 154 \\
\hline Ovipositor length & 111 & 90 \\
\hline $\mathrm{HH}$ & 198 & 163 \\
\hline HW & 195 & 86 \\
\hline Eye height & 124 & 72 \\
\hline Eye breadth & 117 & 69 \\
\hline POL & 63 & 50 \\
\hline $\mathrm{OOL}$ & 29 & 26 \\
\hline LOL & 30 & - \\
\hline Malar sulcus & 43 & 40 \\
\hline $\begin{array}{l}\text { Distance between clypeus } \\
\text { and radicle }\end{array}$ & 32 & 30 \\
\hline Mandible length & 49 & - \\
\hline Mandible height & 19 & - \\
\hline Radicle & 15 & 9 \\
\hline Scape & 104 & 62 \\
\hline Pedicellus & 39 & 42 \\
\hline Total length of anelli & 12 & 10 \\
\hline F1 & 14 & 8 \\
\hline $\mathrm{F} 2$ & 21 & 10 \\
\hline F3 & 24 & 18 \\
\hline F4 & 25 & 24 \\
\hline F5 & 28 & 17 \\
\hline Clava (C1-C3) & 105 & 79 \\
\hline Forewing length & 550 & 449 \\
\hline
\end{tabular}




\begin{tabular}{|l|c|c|}
\hline Forewing breadth & 215 & 156 \\
\hline Hindwing length & 464 & 368 \\
\hline Hindwing breadth & 72 & 41 \\
\hline Fore coxa length & 94 & 50 \\
\hline Fore trochanter length & 17 & 24 \\
\hline Fore femur length & 135 & 103 \\
\hline Fore tibia length & 110 & 92 \\
\hline Fore tibial spur length & 18 & - \\
\hline Fore tarsus length & 105 & 107 \\
\hline Mid coxa length & 60 & 35 \\
\hline Mid trochanter length & 22 & 26 \\
\hline Mid femur length & 134 & 100 \\
\hline Mid tibia length & 157 & 125 \\
\hline Mid tibial spur length & 15 & 15 \\
\hline Mid tarsus length & 102 & 123 \\
\hline Hind coxa length & 116 & - \\
\hline Hind trochanter length & 35 & 25 \\
\hline Hind femur length & 139 & 106 \\
\hline Hind tibia length & 176 & 147 \\
\hline Hind tibial spur length & 13 & - \\
\hline Hind tarsus length & 118 & 36 \\
\hline Prepectus height & 77 & 27 \\
\hline Prepectus breadth & 49 & \\
\hline
\end{tabular}

